\title{
Predictive accuracy of performance oriented mobility assessment for falls in older adults: A systematic review
}

\author{
Seifollah Jahantabi-Nejad ${ }^{1}$, Akram Azad*2 \\ Received: 6 May 2018 \\ Published: 1 May 2019
}

\begin{abstract}
Background: Performance Oriented Mobility Assessment (POMA) is a commonly used screening tool for identifying patients at risk of falling. The purpose of this systematic review was to determine the overall predictive accuracy of POMA for falls in community-dwelling older adults. This review could provide useful information to use POMA in both research and clinical settings.

Methods: In this study, PubMed, EMBASE, CINHAL, Cochrane Library, EBSCO, and SCOPUS were searched to identify studies published from 1987 to 2017 that aimed at validating POMA and reporting predictive value with sufficient data to calculate sensitivity and specificity. The methodological quality of the selected studies was assessed using the Quality Assessment of Diagnostic Accuracy studies (QUADAS-2).

Results: Of the 121 identified studies, 12 met the inclusion criteria and were entered in the final analysis. Fall rate ranged from 5\% to $61 \%$ in the included studies. The POMA cutoff point for discriminating fallers from non-fallers varied from 15 to 26 . Sensitivity and specificity of the POMA ranged from 24-91 to 37-97, respectively.

Conclusion: Due to heterogeneity of the type of studies, participants, the definition of fall, and use of different versions of POMA, it was not possible to determine a specific cutoff point for POMA. In addition, using the same version and scoring method of POMA and controlling the significant potential confounders (eg, age, gender, and comorbidities) would provide better information about the predictive accuracy of POMA for falls in older adults.
\end{abstract}

Keywords: Falls, Older adults, Sensitivity, Specificity, Systematic review

Conflicts of Interest: None declared

Funding: None

*This work has been published under CC BY-NC-SA 1.0 license.

Copyright $₫$ Iran University of Medical Sciences

Cite this article as: Jahantabi-Nejad S, Azad A. Predictive accuracy of performance oriented mobility assessment for falls in older adults: A systematic review. Med J Islam Repub Iran. 2019 (1 May);33:38. https://doi.org/10.47176/mjiri.33.38

\section{Introduction}

Almost one third of older adults aged 60 years and older experience falls at least once a year, which is a major health problem (1). A wide range of fall consequences from mild injury to death has been reported in previous studies, which may cause a significant financial burden on people, the health system, and the community (2). Hence, early identification of individuals at risk of falls is necessary for adopting fall preventive strategies $(3,4)$. Impairments of balance and gait are among the most important reported risk factors for fall in older adults (5). Therefore,

Corresponding author: Dr Akram Azad, azad.a@iums.ac.ir

1. Musculoskeletal Rehabilitation Research Center, Ahvaz University of Medical Sciences, Ahvaz, Iran, \& University of Medical Sciences, Tehran, Iran

2. Rehabilitation Research Center, Department of Occupational Therapy, School of

Rehabilitation Sciences, Iran University of Medical Sciences, Tehran, Iran balance and gait should be considered in evaluating risk of falls in older adults.

Both single- and multi-item instruments can be used to assess risk of falls. Although single-item instruments are a good choice for assessment in time-limited conditions, they have less validity and sensitivity to changes compared to multi-item instruments $(6,7)$. Considering the multifactorial nature of falls, previous studies have suggested the use of multi-item instruments that investigated several risk factors for falls (8). Assessment of risk of

$\uparrow$ What is "already known" in this topic:

Falling is a common problem in older people. It can lead to physical and psychological complications. Balance and gait are two important factor in assessment of risk of falls that should be considered in evaluation.

$\rightarrow$ What this article adds:

This systematic review revealed Performance Oriented Mobility Assessment (POMA) is an appropriate tool for identifying risk of falls in older adults. 
falls is usually performed using multi-item or functional assessment tools. Most of these tools assess only one of the important risk factors for falls, including muscle strength, balance, functional mobility, and gait. For example, chair-standing test evaluates muscle strength, while Timed Up \& Go (TUG) test and Dynamic Gait Index (DGI) assess functional mobility and gait, respectively (9-12). However, Performance Oriented Mobility Assessment (POMA) includes different manoeuvres that require musculoskeletal functions, balance, postural control, and gait. The original version of this test, which has been used in most studies, is the 16-item POMA, with a total score of 28 that includes two subscales of balance and gait. The balance subscale has 9 items (1. sitting balance; 2 . arising; 3 . attempt to arise; 4 . immediate standing balance (first 5 seconds); 5. standing balance; 6 . nudged (subject is at a position with feet as close together as possible, the examiner pushes lightly on the subject's sternum with palm of hand 3 times); 7 . eyes closed (at maximum position \#6); 8. turning 360 degrees; 9. sitting down), with a minimum and maximum score of 0 and 16. The gait subscale has 7 items (1. initiation of gait (immediately after being told "go"); 2 . step length and height; 3. step symmetry; 4. step continuity; 5. path (estimated in relation to floor tiles, 12-inch diameter, observe excursion of a foot over about 10 feet of the course); 6. trunk; 7. walking stance), with a minimum and maximum score of 0 and 12, respectively. Some items (eg, items 1 and 7 of the balance subscale and items 1-4 and 7 of the gait subscale) are scored as 0 (can perform) or 1 (cannot perform), while others (eg, items 2-6, 8 and 9 of the balance subscale and items 5 and 6 of the gait subscale) are scored as 0 (abnormal), 1 (adaptive), or 2 (normal) (13). In addition to the original version, there are several versions of this test with different names and scoring methods (eg, Tinetti Fall Risk Index, Tinetti test, Tinetti Balance Scale, Tinetti Balance and Mobility Score, and Tinetti Performance-Oriented Mobility Assessment). POMA is used as an outcome measure for predicting risk of falls in different populations and has various versions (14-16). Previous studies have confirmed the reliability of POMA in older adults (ICC = 0.75-0.97) (17-21). Concurrent validity of the POMA has also been reported using BBS (0.91) and TUG (-0.68) (9, 17). The sensitivity of this test has been reported to be in a range of $24 \%-95 \%(13,17,22-31)$.

Because of ease of implementation, use of simple equipment, and the minimum need for training, POMA has been used to assess the risk of falls of older adults in different settings, including community settings (13). Hence, it seems reasonable to use POMA as an appropriate tool for identifying fallers and non-fallers and possible reasons for falls in older adults. However, various predictive values of POMA reported in the literature makes it difficult to translate the knowledge for use in clinical setting. Thus, conducting a systematic review may provide useful information to guide its use as an accurate and appropriate screening tool in older adults (32). Therefore, the aim of this systematic review without meta-analysis was to examine the predictive accuracy of POMA to iden- tify risk of falls in older adults.

\section{Methods}

\section{Search strategy}

Different electronic databases, including PubMed, EMBASE, CINHAL, Cochrane Library, EBSCO, and SCOPUS, were searched. The following terms or their combinations [MeSH terms] were used for the search: "Performance-Oriented Mobility Assessment", 'Tinetti Balance and gait scale", "Tinetti Mobility Test", "Tinetti Fall Risk Index", "Tinetti Test", "Tinetti", "POMA", "POMA-B", and "POMA-G". Searches were limited to articles in the English language. Since the original version of POMA (16-item POMA) was developed in 1987, the search included the articles published from 1987 to 2017 (Update 30/3/2018).

\section{Study selection and data extraction}

The inclusion criteria were as follow: (1) studies with participants aged over 60 years who had not comorbid disorders such as stroke, Parkinson's disease, Huntington's disease, and dementia; (2) the sample size of 30 or larger; and (3) studies that reported false negative (FN), false positive (FP), true positive (TP), and true negative (TN) data needed to obtain predictive accuracy of POMA.

Nondiagnostic and diagnostic studies that did not provide enough information about the predictive accuracy of POMA were excluded.

\section{Quality assessment}

The methodological quality of the studies was evaluated by two reviewers based on the Quality Assessment of Diagnostic Accuracy Studies (QUADAS-2), and a third reviewer resolved any disagreement. The agreement percent between authors was 86\%. The QUADAS-2 evaluates the risk of bias and applicability related concerns (31). Items of the risk of bias assessment include patient or sample selection, index test, reference standard, flow and timing. The application of studies in the first 3 cases of these items was also judged by yes (low risk of bias), no (high risk of bias), and unclear options (lack of sufficient information).

\section{Flow and timing}

First, all duplicate publications were excluded. The titles and abstracts as well as full-texts (in case of difficulty judging) were assessed, and studies were selected based on the inclusion and exclusion criteria. Then, data were extracted and entered in evidence table that included the following items: the type and setting of the study, age and gender distribution, cutoff point used in the study, and definition of fall and follow-up period. A $2 \times 2$ contingency table was created and FN, TP, FP, and TN values of the articles were entered in the table. Sensitivity and specificity were assessed to investigate the predictive accuracy of POMA in different studies.

\section{Index test}

Studies in which POMA was used as the only index test or one of the evaluation tools were selected. 


\section{Reference standard}

In the present study, the following definition of fall was considered: "Sudden changes in the body state due to falling on the ground or an object (3)".

\section{Results}

\section{Study selection}

Overall, 133 potentially eligible abstracts were identified. Eight duplicate abstracts were excluded and $101 \mathrm{ab}-$ stracts were also excluded after screening based on the inclusion criteria. By reviewing the full-text of the remaining 24 articles, 12 articles were excluded due to the following reasons: 4 articles were review article, 1 had a sample size less than 30 , and 7 had elderly participants with comorbid disorders. Finally, 12 articles were included in this systematic review (Fig. 1).

\section{Study characteristics}

Of the 12 included studies, 9 were prospective with follow-up period between 6 and 14 months $(13,17.22,23$, $25-28,31)$ and 3 were retrospective and investigated fall history during the past 6 to 12 months using recall form $(24,29,30)$ (Table 1). Eight studies were conducted on community-dwelling older adults (6 prospective and 2 retrospective studies) $(13,22-24,26-28,30), 3$ were done on older adults residing in nursing homes (only prospective studies) $(17,25,31)$, and one on older adults admitted to hospitals (retrospective) (29). The number of partici- pants in 9 included prospective studies ranged from 45 to 1103, with a sample size less than 200 in 7 studies $(17,22$, $23,25-27,31)$ and larger than 200 in 2 studies $(18,28)$. However, the number of participants in 3 included retrospective studies ranged from 34 to 77 and none of these studies had a sample size larger than $200(24,29,30)$ (Table 1). Mean \pm SD age of the participants was in the range of $72.30 \pm 8-84.90 \pm 6$ and $71.60 \pm 6-82.12 \pm 8$ in the included prospective $(13,17,22,23,25-28,31)$ and retrospective studies $(24,29,30)$, respectively (Table 1$)$.

In this study, $50 \%$ to $61 \%$ of the participants in the 9 included prospective studies had experienced falling in the follow-up period. The number of participants of the 3 included retrospective studies who experienced falling in the past year was 27\% (24), 55\% (30), and 59\% (29). Also, $41 \%$ to $83 \%$ of the participants in different included studies were female. Different cutoff points ranging from 15 to 26 , with sensitivity of $24 \%-95 \%$ were reported in different included studies. The use of assistive device was reported by $65 \%$ of all participants in Faber study (17) and $100 \%$ of the participants with a fall history and $72 \%$ of the participants without fall history in Thomas study (30). Of the 12 included studies, ceiling and floor effect was only reported in Faber study (17). The time of falling was not reported in any study. POMA accuracy was reported to range $54 \%-92 \%$ and $64 \%-79 \%$ in the prospective and retrospective studies, respectively.

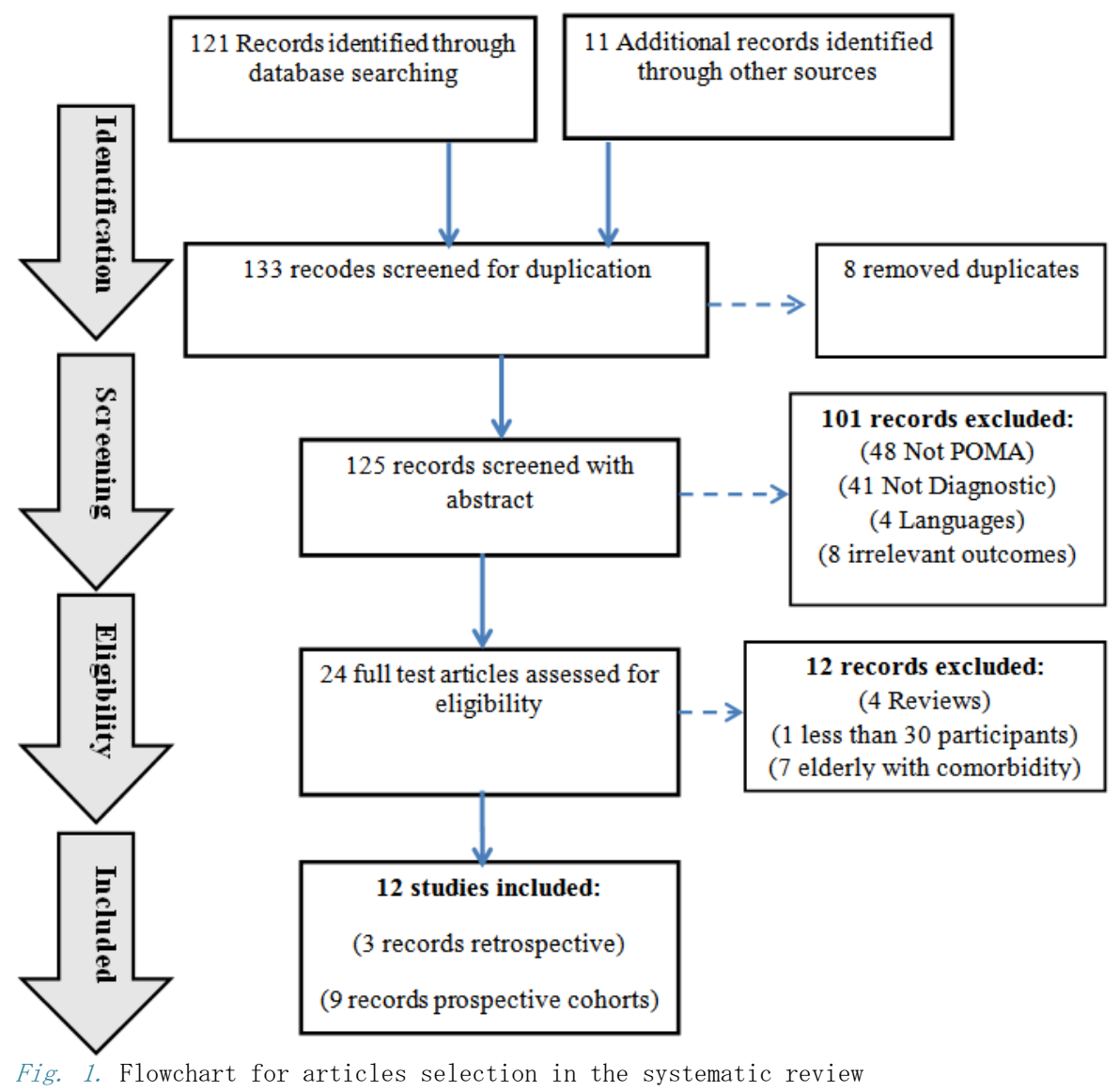




\section{Study quality}

Figure 2 shows a summary diagram of the quality assessment of the 12 included studies. Based on the QUADAS-2, the overall quality of the included studies was moderate. Six studies were rated as low in all domains of applicability concerns and risk of bias $(19,24$, $25,27,28,33)$. There was a high risk of bias for 3 studies $(26,31,32)$ and unclear risk of bias for the remaining studies $(17,29,30)$. Due to the lack of information about participants' selection (ie, selection bias), criteria used for fall definition (eg, reference standard), and lack of followup period, most studies were rated as high or unclear risk of bias. Based on applicability concerns, there was a low, unclear, and high level of concern in $7(17,19,24,25,27-$ $29), 2(30,33)$, and $3(26,31,32)$ studies, respectively.

\section{Predictive accuracy of the included studies}

Among prospective studies, Tinetti (13), Riache (28), and Panzer (27) conducted a study on communitydwelling older adults and used the total score of the original version of the POMA (eg, total score of 0-28), with cutoff point of 15,25 , and 26 , respectively. In the prospective studies of the Trueblood (22), Murphy (23), and
Verghese (26) that investigated the community-dwelling older adults, balance subscale of the POMA with cutoff point of 12,12 , and 10 was used, respectively. The total score of the original version of POMA, with cutoff point of 19, 19, and 20, was used in the prospective studies of the Faber (17), Sharifi (25), and Topper (31), respectively, which were conducted in elderly residents of the nursing care centres (Tables 1 and 2).

Of the retrospective studies conducted in community settings, one study used the total score of the original version of POMA, with cutoff point of 18 (24), and one study used the score of POMA balance subscale (0-16), with cutoff point of 11 (30). The total score of the original version of POMA, with cutoff point of 21 , was only used in Chiu study, which was conducted on older adults admitted to hospitals (Tables 1 and 3).

\section{Sensitivity analysis}

Among 12 included studies, Topper (31) study that used cutoff point of 20 for the total score of the original version of POMA in elderly residents of nursing care centres, reported the highest sensitivity (93\%). Of the studies that used the score of POMA balance subscale, the highest

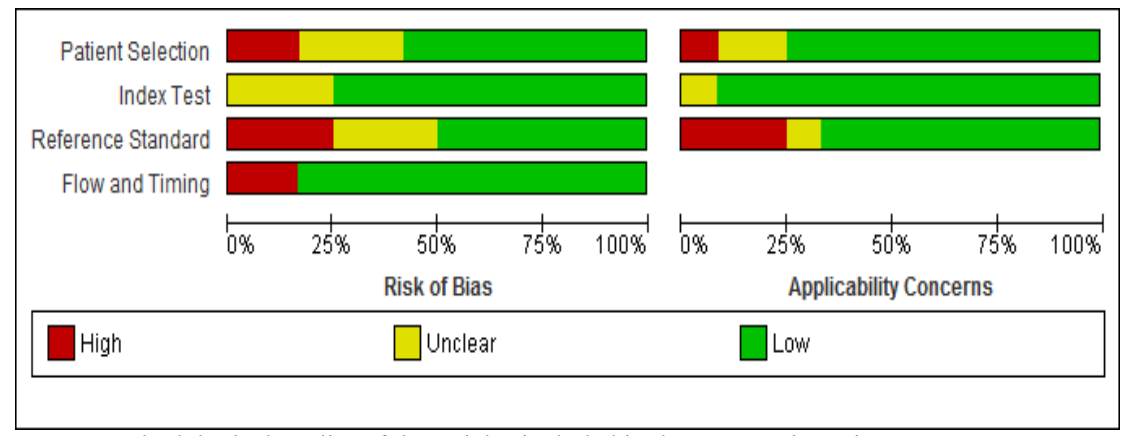

Fig. 2. Methodological quality of the articles included in the systematic review

Table 1. Summary of main characteristics of articles selection in the systematic review without meta-analysis

\begin{tabular}{|c|c|c|c|c|c|c|c|c|c|}
\hline \multirow[t]{2}{*}{ Study } & \multirow{2}{*}{$\begin{array}{c}\text { Design } \\
\text { study }\end{array}$} & \multirow[t]{2}{*}{ Country } & \multirow{2}{*}{$\begin{array}{c}\text { Age } \\
\text { (years) } \\
\text { Mean (SD) }\end{array}$} & \multicolumn{2}{|c|}{$\% \operatorname{Sex}$} & \multirow[t]{2}{*}{ Total } & \multirow[t]{2}{*}{ Faller } & \multirow{2}{*}{$\begin{array}{c}\text { Follow-up } \\
\text { (Month) }\end{array}$} & \multirow[t]{2}{*}{ Setting } \\
\hline & & & & Male & Female & & & & \\
\hline Sharifi F, et al (2015) (25) & $\mathrm{P}$ & Iran & $\begin{array}{c}76.02 \\
(8.82)\end{array}$ & 42.30 & 57.70 & 194 & 52 & 12 & $\begin{array}{l}\text { Nursing Care } \\
\text { Residents }\end{array}$ \\
\hline Panzer VP, et al (2011) (27) & $\mathrm{P}$ & USA & $\begin{array}{l}75.10 \\
(6.50)\end{array}$ & NR & NR & 74 & 47 & 12 & Community \\
\hline Faber MJ, et al (2006) (15) & $\mathrm{P}$ & Netherland & $\begin{array}{l}84.90 \\
(6.00)\end{array}$ & 22 & 78 & 81 & 25 & 10 & $\begin{array}{l}\text { Nursing Care } \\
\text { Residents }\end{array}$ \\
\hline Advic D, et al (2006) (24) & $\mathrm{R}$ & Bosnia & $\begin{array}{l}71.60 \\
(5.60)\end{array}$ & 35.06 & 64.94 & 77 & 21 & 6 & Community \\
\hline Thomas JI, et al (2005) (30) & $\mathrm{R}$ & USA & $\begin{array}{l}81.60 \\
(6.70)\end{array}$ & 46.67 & 53.33 & 30 & 18 & 12 & Community \\
\hline $\begin{array}{l}\text { Murphy MA, et al (2003) } \\
\text { (23) }\end{array}$ & $\mathrm{P}$ & USA & $\begin{array}{l}72.30 \\
(8.60)\end{array}$ & 26 & 74 & 45 & 11 & 14 & Community \\
\hline Chiu AY, et al (2003) (29) & $\mathrm{R}$ & China & $\begin{array}{l}82.12 \\
(8.19)\end{array}$ & 41.18 & 58.82 & 34 & 17 & 6 & Hospital \\
\hline $\begin{array}{l}\text { Verghese J, et al (2002) } \\
\text { (26) }\end{array}$ & $\mathrm{P}$ & USA & $\begin{array}{l}79.60 \\
(6.30)\end{array}$ & 43 & 57 & 59 & 13 & 12 & Community \\
\hline $\begin{array}{l}\text { Trueblood PR, et al (2001) } \\
\text { (22) }\end{array}$ & $\mathrm{P}$ & USA & $\begin{array}{l}77.90 \\
(7.26)\end{array}$ & 20.60 & 79.40 & 180 & 30 & 6 & Community \\
\hline Raiche M, et al (2000) (28) & $\mathrm{P}$ & Canada & $\begin{array}{l}80.00 \\
(4.40)\end{array}$ & NR & NR & 225 & 10 & 12 & Community \\
\hline $\begin{array}{l}\text { Topper AK, et al (1993) } \\
\text { (31) }\end{array}$ & $\mathrm{P}$ & USA & $\begin{array}{l}83.00 \\
(6.00)\end{array}$ & 45.76 & 54.24 & 96 & 58 & 12 & $\begin{array}{l}\text { Nursing Care } \\
\text { Residents }\end{array}$ \\
\hline $\begin{array}{l}\text { Tinetti ME, et al (1986) } \\
\text { (13) }\end{array}$ & $\mathrm{P}$ & USA & $\begin{array}{l}79.60 \\
(5.20)\end{array}$ & NR & NR & 1103 & 546 & 12 & Community \\
\hline
\end{tabular}

Abbreviations: $\mathrm{P}=$ Prospective (A study that involves taking a cohort of information and watching them over a long period.), $\mathrm{R}=$ Retrospective (A historical cohort study that describes research information from the past.), $N R=$ Not Reported 


\begin{tabular}{|c|c|c|c|c|c|c|c|c|c|}
\hline Study & Number fall & $\begin{array}{l}\text { Version } \\
\text { (Score) } \\
\end{array}$ & $\begin{array}{c}\text { Cut-off } \\
\text { point }\end{array}$ & $\mathrm{TP}$ & FP & FN & $\mathrm{TN}$ & Sensitivity & Specificity \\
\hline Sharifi F, et al (2015) (25) & $\geq 1$ & Original $(0-28)$ & 19 & 31 & 68 & 21 & 74 & 60.00 & 52.00 \\
\hline Panzer VP, et al (2011) (27) & $\geq 2$ & Original $(0-28)$ & 26 & 32 & 17 & 15 & 10 & 68.09 & 37.04 \\
\hline Faber MJ, et al (2006) (17) & $\geq 2$ & Original $(0-28)$ & 19 & 16 & 19 & 9 & 37 & 64.00 & 66.10 \\
\hline Murphy MA, et al (2003) (23) & $\geq 1$ & Balance subscale $(0-16)$ & 12 & 6 & 1 & 5 & 33 & 55.00 & 97.00 \\
\hline Verghese J, et al (2002) (26) & $\geq 1$ & Balance subscale $(0-16)$ & 10 & 8 & 14 & 5 & 32 & 61.50 & 69.50 \\
\hline Trueblood PR, et al (2001) (22) & $\geq 1$ & Balance subscale $(0-16)$ & 12 & 7 & 14 & 23 & 136 & 24.00 & 91.00 \\
\hline Raiche M, et al (2000) (28) & $\geq 1$ & Original $(0-28)$ & 25 & 37 & 83 & 16 & 89 & 70.00 & 52.00 \\
\hline Topper AK, et al (1993) (31) & $\geq 1$ & Original $(0-28)$ & 20 & 54 & 5 & 4 & 33 & 91.52 & 89.18 \\
\hline Tinetti MF, et al (1986) (13) & $\geq 1$ & Original $(0-28)$ & 15 & 252 & 173 & 294 & 384 & 46.00 & 69.00 \\
\hline
\end{tabular}

Table 3. Summary of main characteristics of retrospective articles

\begin{tabular}{|c|c|c|c|c|c|c|c|c|c|}
\hline Study & Number fall & $\begin{array}{l}\text { Version } \\
\text { (score) }\end{array}$ & $\begin{array}{c}\text { Cut-off } \\
\text { point }\end{array}$ & $\mathrm{TP}$ & $\mathrm{FP}$ & $\mathrm{FN}$ & $\mathrm{TN}$ & Sensitivity & Specificity \\
\hline Advic D, et al (2006) (24) & $\geq 2$ & Original $(0-28)$ & 18 & 11 & 18 & 10 & 38 & $53.00 \%$ & $68.00 \%$ \\
\hline Thomas JI, et al (2005) (30) & $\geq 1$ & Balance subscale $(0-16)$ & 11 & 15 & 4 & 3 & 11 & $83.00 \%$ & $75.00 \%$ \\
\hline Chiu AY, et al (2003) (29) & $\geq 1$ & Original $(0-28)$ & 21 & 14 & 6 & 3 & 11 & $82.40 \%$ & $64.70 \%$ \\
\hline
\end{tabular}

Abbreviations: $\mathrm{TP}=$ True Positive, $\mathrm{FP}=$ False Positive, $\mathrm{FN}=$ False Negative, $\mathrm{TN}=$ True Negative

sensitivity (83\%) was obtained in Thomas study (30), with cutoff point of 11 in community-dwelling older adults.

Of the 12 included studies, the highest specificity (89\%) was reported for elderly residents of the nursing care centres (31) using cutoff point of 20 for the total score of the original version of the POMA. Of the studies that used the score of POMA balance subscale, the highest specificity $(97 \%)$ was found for community-dwelling older adults, with cutoff point of 12 (23).

Considering both sensitivity and specificity in the studies that used the score of POMA balance subscale, the best cutoff point was 11 (with $83 \%$ sensitivity and $75 \%$ specificity), as reported by Murphy (23). However, of the studies that used the total score of the original version of POMA, the best cutoff point was reported by Topper (31), with $91 \%$ sensitivity and $89 \%$ specificity (Tables 2 and 3 ).

\section{Discussion}

POMA is widely used as a functional tool for predicting falls in older adults. Different manoeuvres performed in POMA are also needed for doing activities of daily living, resulting in widespread use of the POMA in both research and clinical settings. However, generalization of the results of previous studies is difficult due to different study types, target populations, definition of fall, method used to record fall consequences, versions of the POMA used in the studies, cutoff points, and parameters related to predictive power of POMA. This was the first systematic review of the predictive accuracy of POMA for falls in older adults that provides accurate and consistent information about POMA predictive accuracy.

Retrospective studies conducted on POMA were cross sectional studies that reported cutoff points of 11,18 , and $21(24,29,30)$. These studies evaluated balance and gait by POMA and considered fall history in different times. Since various factors may affect balance function, these cutoff points could not be used as optimal cutoff points in clinical or research settings. Moreover, the sample size of retrospective studies conducted on the POMA predictive accuracy was less than 78 and the number of fallers was also very small (eg, less than 22 participants). As deter- mining the cutoff point in diagnostic accuracy studies needs a large sample size, the results of these studies cannot be trusted (Table 3).

In the included prospective studies on POMA predictive accuracy in older adults, cutoff points between 15 and 26 were reported for predicting falls based on the total score of the original version of POMA $(13,17,22,23,25-28$, 31 ). Some of these studies selected the participants from healthy community-dwelling older adults with high level of function, while others selected the elderly admitted to hospitals or nursing care centres. Thus, various populations selected in these studies may be one of the reasons of the heterogeneity of appropriate cutoff point. Another possible explanation for heterogeneity of cutoff point as well as sensitivity and specificity of POMA in older adults may be the different sample size of the included studies, with sample size of equal to or larger than 180 only in 3 studies (Tinetti study, $\mathrm{n}=1103$ (13); Riache study, $\mathrm{n}=$ 225 (28); and Trueblood study, $\mathrm{n}=180$ (22)). Since the number of fallers was very small (equal to or less than 30 ) in 2 of the 3 studies, all the included prospective studies, except for the Tinetti study, have a disadvantage in sample size and number of fallers and cannot be cited. On the other hand, cutoff points of 25 and 26 were reported in some included prospective studies $(27,28)$ that are near the ceiling effect of POMA. Therefore, these cutoff points cannot be appropriate for detecting risk of falls in all older adults. Furthermore, some of the included prospective studies $(22,23,26)$ only used the balance subscale of POMA. Because falling depends on mobility and gait in addition to balance, the results of these studies cannot be used to predict risk of falls in older adults. Two of these 3 studies $(22,23)$ reported cutoff point of 12 , which is near a ceiling effect of POMA balance subscale. Hence, this cutoff point is also questionable. Thus, only the prospective study of Tinetti, conducted on community-dwelling older adults with a large sample size $(\mathrm{n}=1103)$, was suitable for determining the diagnostic accuracy of the original version of POMA for risk of falls. However, due to very low sensitivity (46\%) and specificity (69\%) of the POMA in this study, the cutoff point of this study (i.e. 17) 
cannot be used as an optimal cutoff point for predicting risk of falls in older adults (Table 2). Thus, further studies are warranted to determine the optimal cutoff point of the POMA to predict risk of falls in older adults.

The heterogeneity of type of studies, outcome measures, and settings precluded meta-analysis, and thus a better standardization of assessment condition based on a protocol explained in the original version of the POMA (i.e, 16item POMA) should be used in future studies to assess risk of falls in older adults using POMA.

Considering the heterogeneity of type of studies, target populations, number of fallers, and type of POMA subscale used in the included studies, a specific cutoff point of POMA cannot be suggested for predicting risk of falls in older adults.

\section{Conclusion}

The results of this article are useful for all therapists, particularly occupational therapists who work in the field of aging and need a good tool for predicting risk of falls in older adults. POMA is an appropriate tool for identifying risk of falls in older adults, which can be used in both research and clinical settings.

\section{Acknowledgement}

This paper was extracted from a $\mathrm{PhD}$ thesis on occupational therapy in School of Rehabilitation Sciences, Iran University of Medical Sciences, Tehran, Iran.

\section{Conflict of Interests}

The authors declare that they have no competing interests.

\section{References}

1. Park SH, Lee YS. The diagnostic accuracy of the Berg Balance Scale in prediction falls. West J Nurs Res. 2017;39(11):1502-25.

2. Yamashita T, Noe DA, Bailer AJ. Risk factors of falls in communitydwelling older adults: logistic regression tree analysis. Gerontologist. 2012;52(6):822-32.

3. Nevitt MC, Cummings SR, Hudes ES. Risk factors for injurious falls: A prospective study. J Gerontol. 1991;46(5):M164-70.

4. Jazaeri SZ, Azad A, Mehdizadeh H, Habibi SA, Najafabadi MM, Saberi ZS, et al. The effects of anxiety and external attentional focus on postural control in patients with Parkinson's disease. PLoS One. 2018;13(2):e0192168.

5. Rubenstein LZ. Falls in older people: Epidemiology, risk factors and strategies for prevention. Age Ageing. 2006;35(2):37-41.

6. Diamantopoulos A, Winklhofer HM. Index construction with formative indicators: An alternative to scale development. J Mark Res. 2001;38(2):269-77.

7. Taghizadeh G, Azad A, Kashefi S, Fallah S, Daneshjoo F. The effect of sensory-motor training on hand and upper extremity sensory and motor function in patients with idiopathic Parkinson disease. J Hand Ther. 2018;31(4):486-93.

8. Scott V, Votova K, Scanlan A, Close J. Multifactorial and functional mobility assessment tool for fall risk among older adults in community, home-support, long-term and acute care settings. Age Ageing. 2007;36:130-9.

9. Berg KO, Wood-Dauphinee SL, Williams JI, Maki B. Measuring balance in the elderly: Validation of an instrument. Can J Public Health. 1992;83(2):S7-11.

10. Hernandez D, Rose DJ. Predicting which older adults will or will not fall using the 30-second chair stand test. Arch Phys Med Rehabil. 2008;89(12):2309-3315.

11. Herman T, Inbar-Borovsky N, Brozgol M, Giladi N, Hausdorff JM. The dynamic gait index in healthy older adults: the role of stair climb- ing, fear of falling and gender. Gait Posture. 2009;29(2):237-41.

12. Podsiadlo D, Richardson S. The timed "Up \& Go": A test of basic functional mobility for frail elderly persons. J Am Geriatr Soc. 1991;39(2):142-8.

13. Tinetti ME. Performance-oriented assessment of mobility problems in elderly patients. J Am Geriatr Soc. 1986;34(2):119-26.

14. Yucel SD, Sahin F, Dogu B, Kursakal S, Sahin T, Kuran B, et al. Reliability and validity of Turkish version of the PerformanceOriented Mobility Assessment. Eur Rev Aging Phys Act. 2012;9:149-59.

15. Park J, Koh SB, Oh E, Kim JS, Yun JU, Kown DU, et al. Validity and reliability study of Korean Tinetti mobility test for Parkinson disease. J Mov Disord. 2018;11(1):24-9.

16. Schulien S, Pflugard L, Petersen H, Lutz M, Volland Schussel K, et al. German translation of performance oriented mobility assessment according to Tinetti. Z Gerontol Geriatr. 2017;50(6):498-505.

17. Faber MJ, Bosscher RJ, Van Wieringen PC. Clinometric properties of the performance-oriented mobility assessment. Phys Ther. 2006;86(7):944-54.

18. McGinty SM, Masters LD, Till DB. Inter-tester reliability using the Tinetti gait and balance assessment scale. Issues Aging. 1999;22:3-5.

19. Mecagni C, Smith JP, Roberts KE, O'Sullivan SB. Balance and ankle range of motion in community-dwelling women aged 64-87 years: A correlational study. Phys Ther. 2000;80(10):1004-11.

20. Protas EJ, Harris C, Moch C, Rusk M. Sensitivity of a clinical scale of balance and gait in frail nursing home residents. Disabil Rehabil. 2000;22:372-8.

21. Harada N, Chiu V, Fowler E, Lee M, Reuben DB. Physical therapy to improve functioning of older people in residential care facilities. Phys Ther. 1995; 75(9): 830-8.

22. Trueblood PR, Hodson-Chennault N, McCubbin A, Young clarke D. Performance and impairment-based assessments among community-dwelling elderly: Sensitivity and specificity. Issues Aging. 2001;24(1):2-6.

23. Murphy MA, Olson SL, Protas EJ, Overby AR. Screening for falls in community-dwelling elderly. J Aging Phys Act. 2003;11:66-80.

24. Avdic D, Pecar D. Significance of specificity of B-POMA test and fall risk factor in the third age of life. Bos $\mathrm{J}$ Basic Med Sci. 2006;6(1):50-7.

25. Sharifi F, Fakhrzadeh H, Memari A, Najafi B, Nazari N, Khoee MA, et al. Predicting risk of the fall among aged adult residents of a nursing home. Arch Gerontol Geriatr. 2015;61(2):124-30.

26. Verghese J, Buschke H, Viola L, Katz M, Hall C, Kuslansky G, et al. Validity of divided attention tasks in predicting falls in older individuals: A preliminary study. J Am Geriatr Soc. 2002;50(9):1572-6.

27. Panzer VP, Wakefield DB, Hall CB, Wolfson LI. Mobility assessment: Sensitivity and specificity of measurement sets in older adults. Arch Phys Med Rehabil. 2011;92(6):905-12.

28. Raiche M, Hebert R, Prince F, Corriveau H. Screening older adults at risk of falling with the Tinetti balance scale. Lancet. 2000;356(9234):1001-2.

29. Chiu AY, Au-Yeung SS, Lo SK. A comparison of four functional tests in discriminating fallers from non-fallers in older people. Disabil Rehabil. 2003;25(1):45-50.

30. Thomas JI, Lane JV. A pilot study to explore the predictive validity of 4 measures of falls risk in frail elderly patients. Arch Phys Med Rehabil. 2005;86(8):1636-40.

31. Topper AK, Maki BE, Holliday PJ. Are activity-based assessments of balance and gait in the elderly predictive of risk of falling and/or type of fall? J Am Geriatr Soc. 1993;41(5):479-87.

32. Kopke S, Meyer G. The Tinetti test. Babylon in geriatric assessment. Z Gerontol Geriat. 2006;39:288-91.

33. Whiting PF, Rutjes AW, Westwood ME, Mallett S, Deeks JJ, Reitsma JB, et al. QUADAS-2: A revised tool for the quality assessment of diagnostic accuracy studies. Ann Intern Med. 2011;155(8):529-36. 